Egyptian Journal of Aquatic Biology \& Fisheries

Zoology Department, Faculty of Science,

Ain Shams University, Cairo, Egypt.

ISSN $1110-6131$

Vol. 25(2): 509 - 522 (2021)

www.ejabf.journals.ekb.eg

\title{
Reusing and Characterization of the Used Reverse Osmosis Membrane and its Application in Surface Water Purification
}

Mohamed R. El-Aassar ${ }^{1,2}$, Ahmed A. Elzain ${ }^{3}$, Fayza S. Hashem ${ }^{3}$, Fathy M. Mohamed ${ }^{4 *}$

${ }^{1}$ Chemistry Department, College of Science, Jouf University, Sakaka- 2014, Saudi Arabia.

${ }^{2}$ Polymer Materials Research Department Advanced Technology and New Material Institute,

City of Scientific Research and Technological Applications (SRTA City, Alexandria, Egypt.

${ }^{3}$ Chemistry Department, Faculty of Science, Ain Shams University, P.O. 11566 Cairo, Egypt.

${ }^{4}$ Hydrogeology and Environment Department, Faculty of Earth Sciences, Beni-Suef University, Beni-Suef, Egypt.

*Corresponding author: fathy1973@esc.bsu.edu.eg

\section{ARTICLE INFO}

Article History:

Received: April 9, 2021

Accepted: April 22, 2021

Online: April 23, 2021

\section{Keywords:}

Used RO membrane;

characterization;

polyamide;

conventional technique;

surface water

purification.

\section{ABSTRACT}

The current study concerns the recycling of the used reverse osmosis membrane named DOW FILMTECTM SW30HR-380. The performance improvement includes the following steps:(1) Molecular characterization of the used membrane where it contributes to understanding the physico-chemical properties of reverse osmosis membranes and their performance, using different analytical techniques like FTIR, SEM and tensile strength. (2) reuse of the Polysulfone layer of the membrane as a filter for the turbidity removal of surface water.(3) Comparison between the turbidity removal \% by the Polysulfone layers (arranged in a disc filter) and the conventional coagulants. From the results, we found that SEM photographs were an evidence for the high fabrication of the membrane. The coating layer showed a high hydrophilic hydroxyl group appearing in FTIR spectra. Mechanically, the polyamide layer showed the best tensile properties. Raw water quality and the conditions leading to filter clogging were discussed. The removal percentage of turbidity and algae from surface water reached 60 and $80 \%$ respectively using five successive Polysulfone layers with a surface area of $12.5 \mathrm{~cm}^{2} /$ layer. At the same turbidity, tested coagulants achieved higher removal \% than that of the Polysulfone layers. On one hand, the recycled reverse osmosis membrane may be used as an alternative technique for removing turbidity and algae, while on the other hand, it reduces harmful effects and emissions

\section{INTRODUCTION}

Reverse osmosis is an experiencing exponential growth as it has become the most important technology for desalination of seawater. Thus various preparation techniques were applied to produce reverse osmosis membranes from different materials, exhibiting a high performance, salt rejection and a significant impact on the design (Altaee 2012; Yang et al., 2019 ). Chemically, aromatic interfacial composite membrane was developed by Cadotte, at FilmTec, based on the reaction of phenylenediamine and trimesoyl chloride since the reaction of aromatic amine monomers and aromatic acid chloride 
monomers produces a polyamide layer of several hundred nanometers thickness ( ElDessouky and Ettouney 2002; Yang et al., 2019). In Egypt, due to the limited water supplies and water scarcity, the Governorate has begun to expand the desalination plants as a source of drinking water, especially in the coastal areas with a production capacity of $300,000 \mathrm{~m}^{3} /$ day, reaching 3 million $\mathrm{m}^{3} /$ day in 2037, the membrane 's lifetime is about 5 years and thus the rate of membrane consumption ( Starr et al., 2019). This quantity of consumed membranes reflects an alarming environmental burden which could only be redirected to specific applications such as wastewater reuse, surface water treatment or improvement of active layers. The costs were calculated through both the energy consumption and the cost of replacing membranes remain a major concern for reverse osmosis systems.From this economic point of view, we are looking to use the membrane layers in various applications.The objectives of this work is to transform the used membranes from the source of environmental pollution to a means of reducing environmental pollution by using them as alternatives to new imported membranes and to reduce the costs of removing surface water turbidity in current filtration system. Several scientests have been studied the removal of turbidity from wastewater ( Abo-El-Enein, $\boldsymbol{e t}$ al., 2011; Sasikala and Muthuraman, 2017; Gaikwad and Munavalli, 2019) Mohamed and Alfalous, 2020) total suspended solids( Mohamed et al., 2019 ), algal removal ( Mohamed et al., 2020a).

The current work estimated the characterization of SW30HR reverse osmosis membrane using different analytical techniques like FTIR, SEM and tensile strength where it contributes in understanding the physico-chemical properties of reverse osmosis membranes, their performance, and the interaction between membranes and contaminants in water. Then, recycling the Polysulfone layer of the membrane as a disc filter for surface water treatment, as well as comparative study between the used membranes and conventional water treatment techniques.

\section{MATERIALS AND METHODS}

\subsection{Materials}

Certain organic solvents such as (dimethyl sulfoxide, dimethyl formamide, toluene, cyclohexane, etc.) were obtained from Sigma Aldrich (Germany). Also, Ferric Chloride (coagulant) from Sigma Aldrich (Germany), Alum was obtained from the Egyptian Alum Co. (Egypt), and Hydrex coagulants were obtained from Veolia (France).

\subsection{Methods}

\subsubsection{Membrane Description}

Figure (1A) illustrated the design of the used commercial membrane in this study DOW FILMTEC ${ }^{\text {TM }}$ SW30HR-380 Film Composite membrane, which consists of: (1) Barrier layer of ultra-thin polyamide which is about $2000 \mathrm{~A}^{\circ}$ thick providing high resistance to chemical degradation and mechanical stress, the chemical structure was shown in Figure (1B), (2) Support web of polyester which is excessively porous to give an appropriate substrate for the salt barrier layer,(3) Polysulfone microporous interlayer which was upgraded to provide high water permeability at high pressure ( Separations, 2004). 


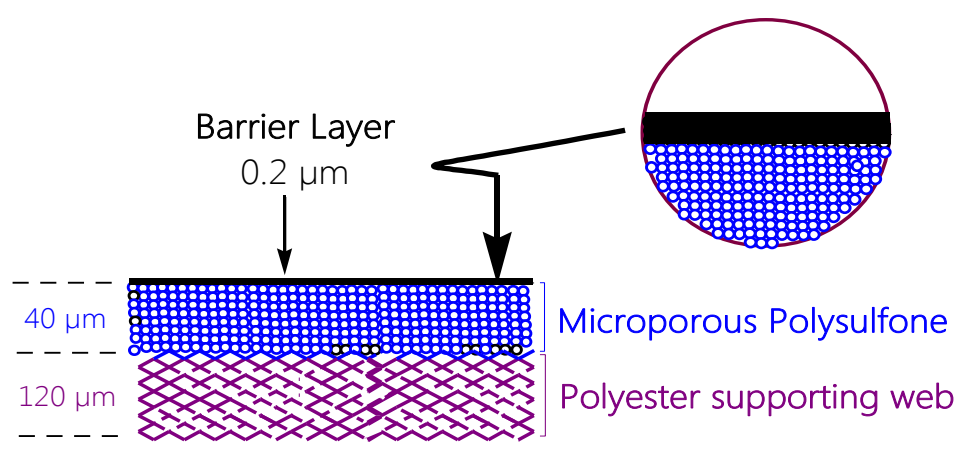

Figure ( 1A): Cross-section of FILMTEC Thin Film Composite membrane<smiles>CNc1cccc(NC(=O)c2cc(C(N)=O)cc(C(=O)Nc3cccc(NC(=O)c4cc(C(=O)O)cc(C(=O)O)c4)c3)c2)c1</smiles>

Figure (1B): Chemical structure of polyamide layer of membrane

\subsubsection{Membranes startup performance for seawater desalination}

In this research, the reverse osmosis membrane model was DOW FILMTECTM SW30HR-380 for high rejection of seawater. It is a spiral-wound element with polyamide thin-film composite membrane; its active area is $35 \mathrm{~m}^{2}$, the thickness of its feed spacer is $28 \mathrm{~mm}$. This membrane model was designed to produce $24.6 \mathrm{~m}^{3} /$ day of permeated water with $99.7 \%$ salt rejection( Separations, 2004). The membrane was used in Cleo-Patra plant for seawater desalination, Matrouh Company for water and wastewater, Egypt. Cleo-Patra plant gets its feed water from a beach well intake from the Mediterranean Sea, which is located about 100 meters far from the beach and about 100meter depth. Cleo-Patra desalination plant production rate is $4.500 \mathrm{~m}^{3} / \mathrm{day}$. After the operational lifetime of the membrane, the membrane was replaced and taken for further investigation into laboratory where it undergoes chemical cleaning.

\subsubsection{Chemical cleaning of the used membrane}

The chemical cleaning into lab was done where $100 \mathrm{~mm}^{2}$ of SW30HR380 reverse osmosis membrane was immersed in $0.1 \% \mathrm{NaOH}$ and $1 \% \mathrm{Na}_{2}$ EDTA solution with shaking for 90 minutes at room temperature to get rid of sulfate scales, fluoride, biofilms and organic fouling. Then, the membrane undergoes successive washing with distilled water to be immersed into $0.2 \mathrm{wt} \% \mathrm{HCl}$ for 60 minutes at room temperature to remove carbonate and phosphate scales. Finally, the membrane undergoes another successive washing with distilled water, drying at $50{ }^{\circ} \mathrm{C}$ for 60 minutes and kept at $4{ }^{\circ} \mathrm{C}$ in sterile bottles to prevent microbial growth. 


\subsubsection{Application of Polysulfone layers for turbidity removal.}

The Polysulfone layers of the used membrane were cut into discs, arranged in the form of a cylindrical multilayer filter for fine filtration. Polysulfone layers were uniformly and precisely distributed in a certain sequence with active surface area12.5 $\mathrm{cm}^{2} /$ layer. The layers acted as a barrier for the turbidity of the diffused water. Turbidity was measured by HACH turbidity meter/ model TL2310/Germany. The removal efficiency achieved by the filters was calculated, Equation 1:

Removal Efficiency $\%=\left(\left(\mathbf{C}_{0}-\mathbf{C}\right) / \mathbf{C}_{0}\right) * 100$

$\mathrm{C}_{\mathrm{o}}$ is the unfiltered effluent turbidity (NTU), and $\mathrm{C}$ is the filtered effluent turbidity after filtration (NTU).

\subsubsection{Sample collection:}

Water samples were collected from El-Hamam Canal of El-Nasr canal, branched from El-Nubria Canal, Marsa Matrouh Governorate, Egypt. The sampling location is determined using latitude and longitude on the map as shown in Figure (2).

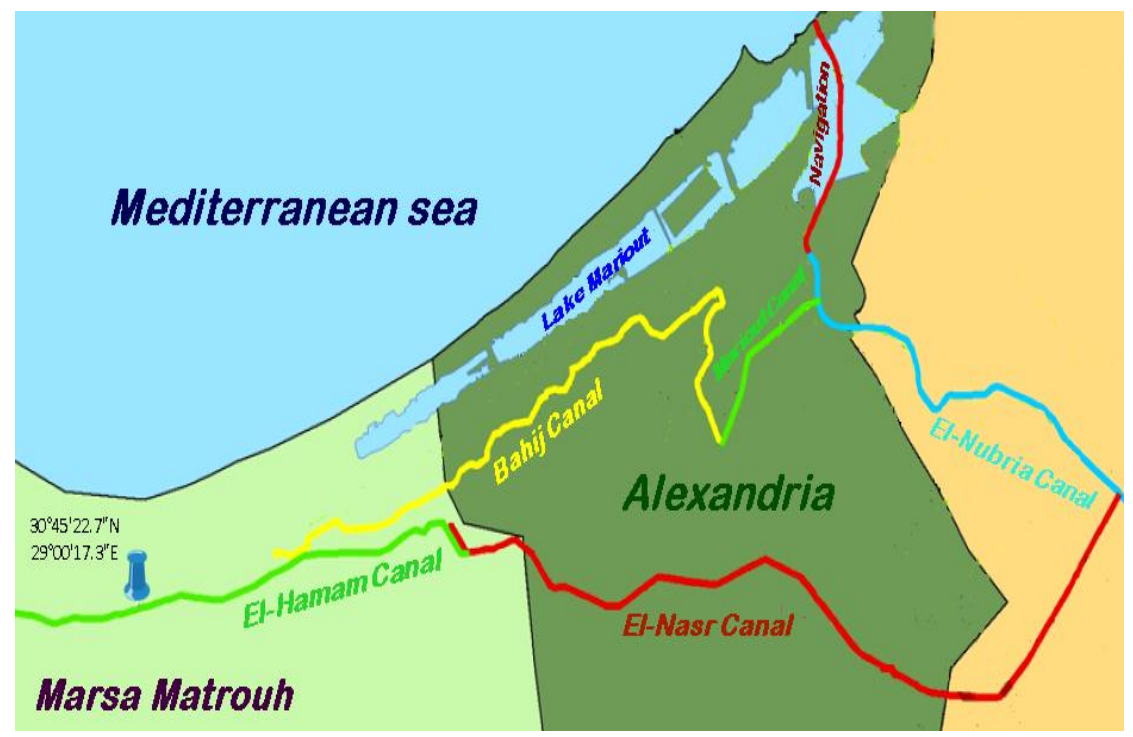

Figure (2): Location of water sampling

\subsubsection{Application of commercial co-agulants for turbidity removal.}

One litre of each sample was mixed with 1-2 ppm of hydrex coagulants such as hydrex 67516, 6143, 6783 and 6161 and agitated for 1min rapid mixing (200 rpm), followed by slow mixing for five minutes and $(50 \mathrm{rpm})$ and $20 \mathrm{~min}$ standing time. However, in the case of alum and ferric chloride the doses were 10-16 ppm. Turbidity was measured by HACH turbidity meter/ model TL2310/Germany.

\subsubsection{Testing the membrane stability towards chemical degradation}

The SW30HR380 reverse osmosis membrane layers were tested for different types of organic solvents with and without heating. The membrane shows high resistance to solvents such as dimethyl formamide, ethyl acetate, acetone, dimethyl sulfoxide, ethanol, methanol, isobutanol, acetic acid, etc. The result was that SW30HR membrane showed a high resistance towards chemical degradation similar to that of other polyamides. 


\subsection{Characterization of membrane layers}

\subsubsection{Scanning electron microscopic (SEM) analysis}

The surface of SW30HR layers was scanned to investigate their morphological structure using SEM (JEOL JSM 6360LA, Japan) at an accelerated voltage of $20 \mathrm{KV}$. The fracture surface was vacuum coated with gold and was examined at different magnifications.

\subsubsection{Fourier Transform Infrared Spectroscopic (FTIR) analysis}

FTIR spectra of SW30HR layers were investigated over a wavelength 400-4,000

$\mathrm{cm}^{-1}$ using Fourier transform infrared spectrophotometer (FTIR) (Shimadzu FTIR-8400 S, Japan).

\subsubsection{Tensile performance}

Tensile test for SW30HR membrane layers was performed by following the ASTM D882 standard test method using the AG-10kNIS MS (Shimadzu Corporation, Kyoto, Japan) at the crosshead speed of $5 \mathrm{~mm} / \mathrm{min}$. The test was carried out at room temperature.

\subsection{Comparative study for different coagulant on turbidity removal}

In order to evaluate a comparison between the applied procedure in this study for turbidity removal and other conventional techniques, different commercial coagulants such as (Ferric Chloride, Alum, and Hydrex) were tested for turbidity removal. The experiments were carried out using jar test, model ;VelpScientifica FC4S Flocculator,Italy.

\section{RESULTS}

\section{1. Feed and permeate analysis}

During the membrane startup, the feed water and the permeated water were physically and chemically tested. All parameters of the permeated water through the membrane were within the accepted limits of Egyptian Minister of Health decree no 458/2007 for drinking water as shown in Figure (3). The data showed the salt rejection rate of the membrane to be $99.3 \%$.Langelier index and a Ryznar index indicating the permeated water to be corrosive where their values were -2.22 and 11.37 respectively. For the feed water they were -0.78 and 8.94 respectively, it is also corrosive water. The membrane shows $99.4 \%$ of chlorides rejection where chloride ions are generally well rejected by thin film polyamide membranes with values in the range of $99.7-99.8 \%$ ( Lomax, 2008). The total dissolved solids, materials pass through a $2 \mu \mathrm{m}$ filter, the value of the feed water was $41.202 \mathrm{mg} / \mathrm{l}$ where it can reach 170,000 mg/L ( Rice and Nuccio, 2000). Also, the permeate TDS value meets the recommended TDS for potable water which is less than $500 \mathrm{mg} / \mathrm{L}$ and $1000-2000 \mathrm{mg} / \mathrm{l}$ for beneficial applications (Mondal and Wickramasinghe, 2008). Physically, colorless and odorless water with turbidity less than 1 NTU was permeated from the membrane. $\mathrm{pH}$ value of the feed water was decreased from 7.38 to 6.92 . The removal percent of silicates and sulfates were $99.3 \%$ and $99.8 \%$, respectively. Bicarbonates were decreased from $160 \mathrm{mg} / \mathrm{l}$ to $55 \mathrm{mg} / \mathrm{l}$ across the membrane while seawater was free from carbonates and hydroxides. Cupper, Iron, and Manganese were undetected in the permeate. The hardness of the feed was disappeared to get soft permeate water. Ammonia and nitrites have the same removal percent, $80 \%$, while for nitrates, it was $75 \%$. 


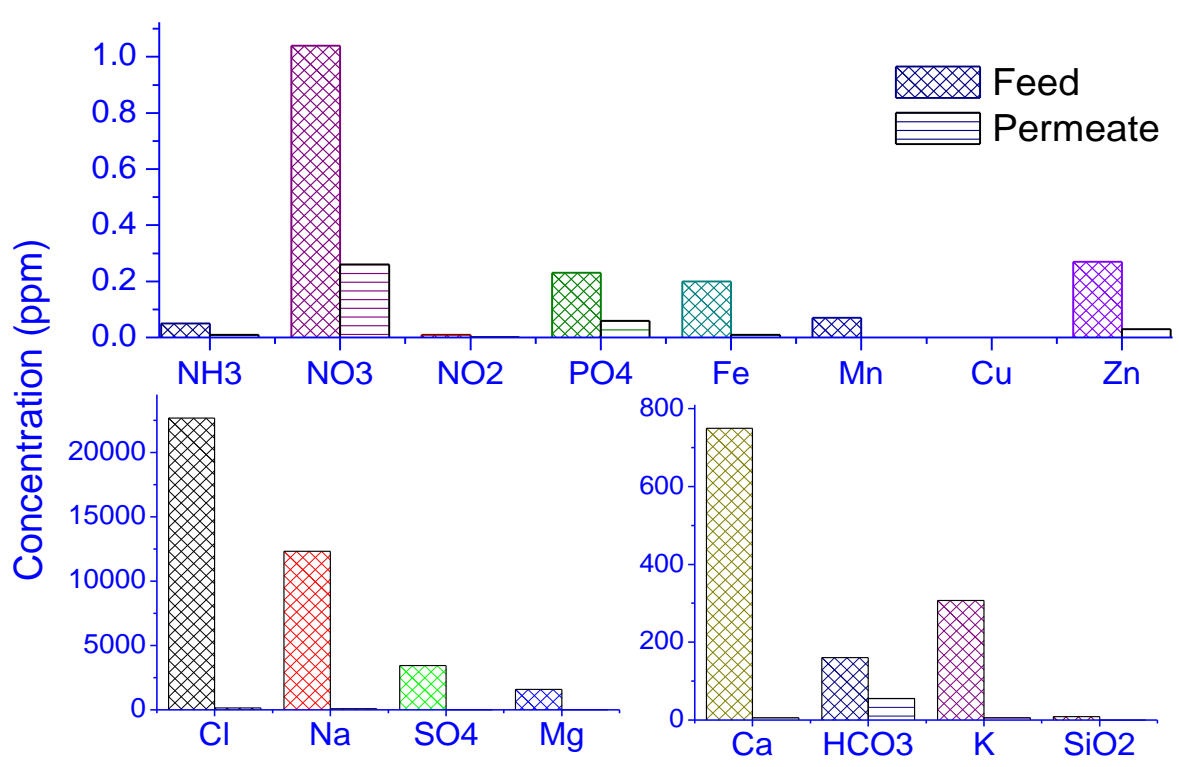

Figure 3: Chemical parameters concentration of water in Feed and permeate of SW30HR-380 RO

The appearance of residual chlorine in the permeated water is due to the post disinfection process after the RO stage. After about two years of membrane working hours, the probing test result showed the membrane to be replaced. The membrane undergoes chemical cleaning program if one of the following problems appears(1) reduction of productivity by 10\%,(2) increase of salinity by $10 \%$ (3) decrease of trans pressure by $15 \%$ ( Nikolay, 2013). If the chemical cleaning failed, the membrane must be replaced by another new one. The old one was eliminated and a portion of it was cut to get the facility of its use into the laboratory.

\subsection{Characterization of SW30HR membrane \\ 3.2.1 Scanning Electron Microscope (SEM)}

The Scanning Electron Microscope (SEM) play a vital role in the evaluation of the morphological structure of polymeric materials ( El-Aassar, et al, 2019 ; Alsohaimi et al., 2020). Figure (4), SEM photographs shows a ridge and valley structure which is a unique surface structure of FT-30 polyamide layer while smooth surfaces are characteristic to those membranes obtained from aliphatic amines ( Lee et al., 2011).In addition to the partial distortion of this unique structure was appeared in SEM photographs, due to membrane working for a long time under pressure and frequent chemical cleaning which reduces its efficiency. It was reported that this unique structure increases water flux through its high effective surface area ( Kwak et al., 1999). The coating layer was clear in the cross-section. The SEM showed the high fabrication of the Polysulfone layer where studies found it a perfect material for the support layer depending on its resistance to compaction ( Rozelle, et al., 1968; Davenport et al., 2020). Finally, SEM showed all membrane layers to be covered by rejected solutes and particulate matters after membrane working. 

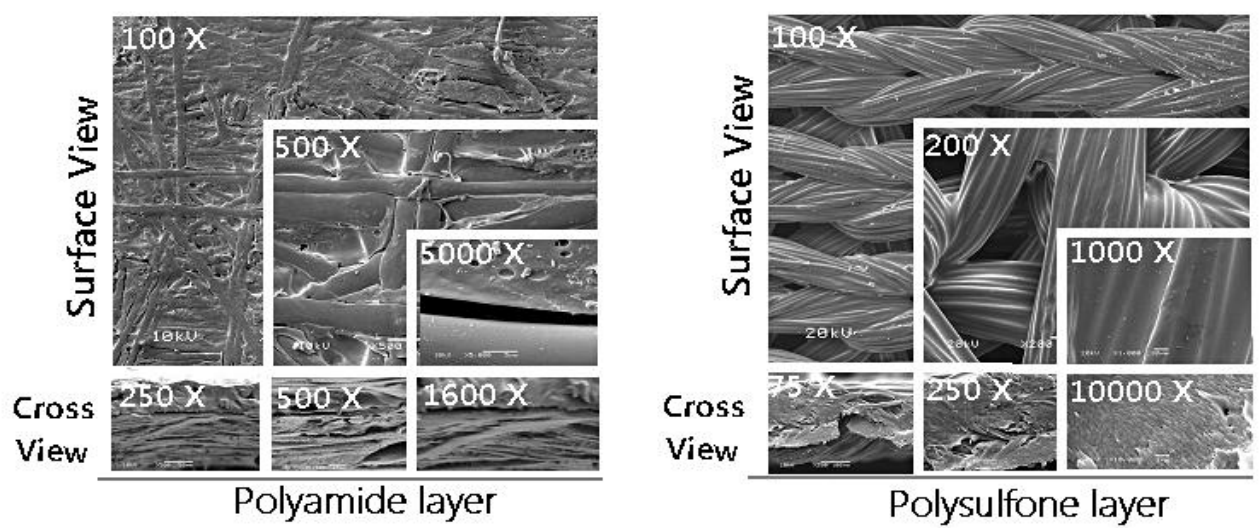

Figure (4): SEM photographs of Polyamide and Polysulfone layers of membrane.

\subsubsection{Fourier Transform Infra-Red Spectra (FTIR)}

It was reported that SW30HR membranes have been commercially coated with a hydrophilic neutral, mostly aliphatic, coating layer rich in $\mathrm{NH}$ group which appeared clearly in FTIR spectra at $3674 \mathrm{~cm}^{-1}$, Figure (5) ( El- Aassar et al., 2018). The broad band around $3400 \mathrm{~cm}^{-1}$ was evaluated by overlapping between vibration stretching of the hydroxyl group of $\mathrm{OH}$ of the polyamide layer, and $\mathrm{O}-\mathrm{H}$ groups from the coating layer. For polyamide, this peak of N-H group split into two peaks at $3458 \mathrm{~cm}^{-1}$ and $3591 \mathrm{~cm}^{-1}$ which represent free and hydrogen-bonded $\mathrm{N}-\mathrm{H}$ stretching modes, respectively( El- Aassar et al., 2018 ;El-Aassar and Mohamed (2021). However, only one peak around $3419 \mathrm{~cm}^{-1}$ with appeared at FTIR spectra of Polysulfone. The peaks around 3000 $\mathrm{cm}^{-1}$ correspond to $\mathrm{C}-\mathrm{H}$ vibration( Elzain et al., 2019). Peaks around $3000-3100 \mathrm{~cm}^{-1}$ correspond to aromatic $\mathrm{C}-\mathrm{H}$ stretching vibrations (Silverstein et al., 2014). Presence of the Polysulfone interlayer was confirmed by peaks at $702 \mathrm{~cm}^{-1}, 1132 \mathrm{~cm}^{-1}, 1466 \mathrm{~cm}^{-1}$, $1503 \mathrm{~cm}^{-1}$ and $1527 \mathrm{~cm}^{-1}$. While Peaks at $1700 \mathrm{~cm}^{-1}$ is unique for polyamide membranes as it represents the stretching to the $\mathrm{C}=\mathrm{O}$ stretching of $\mathrm{CO}-\mathrm{NH}_{2}$ group( Elzain et al., 2019; El-Aassar, et al.,2019).

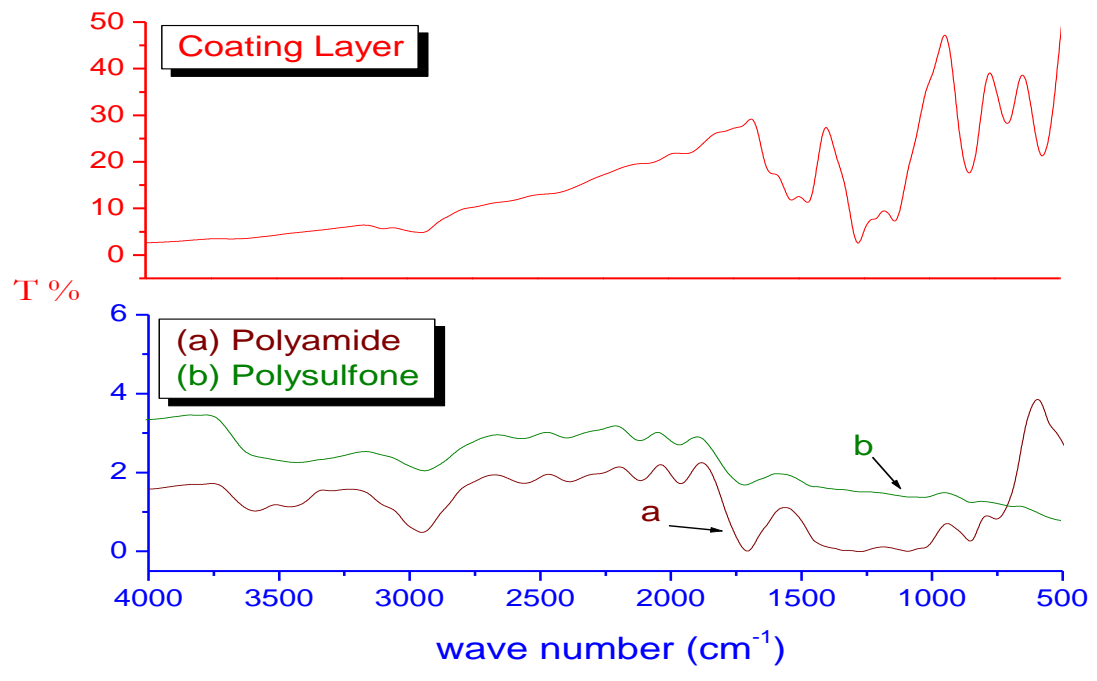

Figure (5): Fourier Transform Infra-Red Spectra of membrane layers: polyamide, the coating layer, and Polysulfone. 


\subsubsection{Tensile Performance}

Polyester web showed the highest stroke strain \% where the polyamide layer showed the best tensile properties (Fig. 6), where the aromatic structure of polyamide enhances the membrane resistance towards compression and increase its chemical and thermal stability ( Lee et al., 2011). The layers mechanically obey Hooke's law where the stress is directly proportional to the strain for strains up to the elastic limit. Depending on the loading type, Young's modulus (E) was applied to the curve. Young's modulus was experimentally determined from the slope of the stress-strain curve created during tensile tests. Young's modulus values showed the polyamide layer to be the most stiffness layer through the membrane and its value not far from that of Polysulfone while the polyester web was the lowest stiff layer.

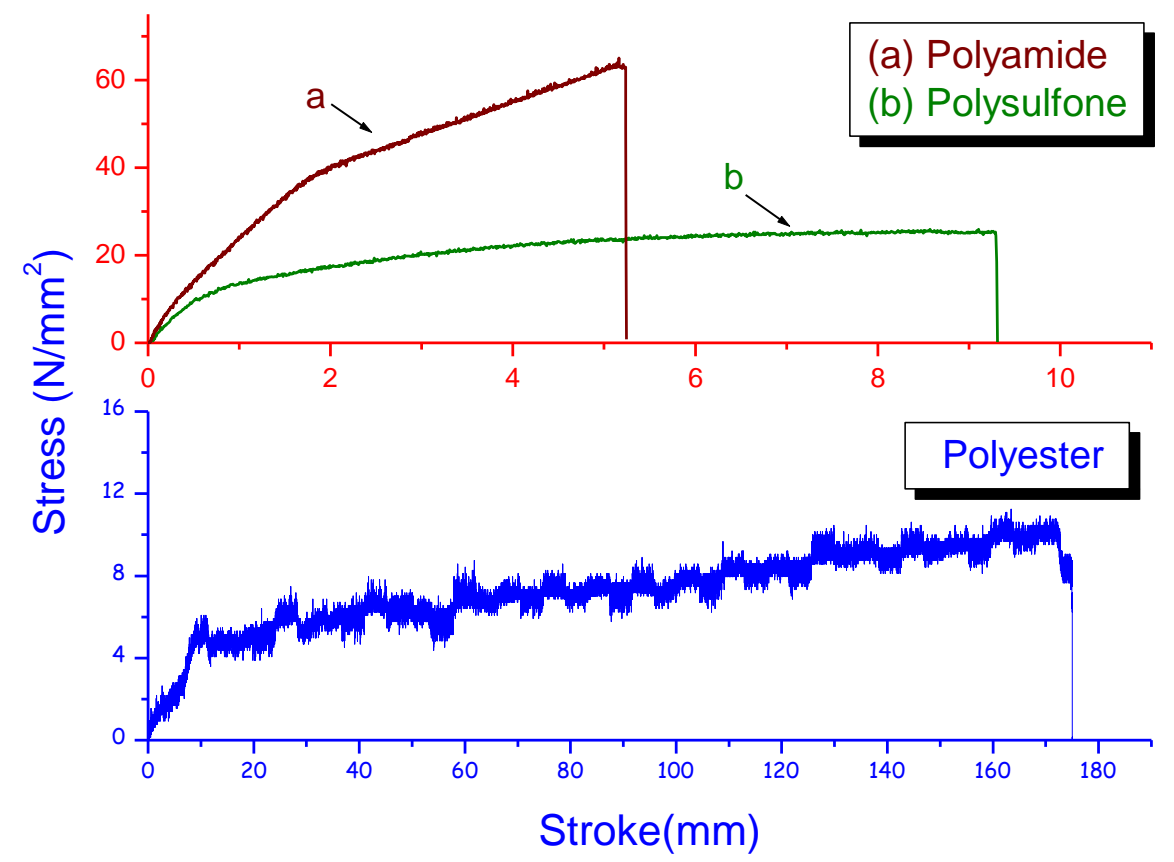

Figure (6): Stress-Strain curve of polyamide, Polysulfone, polyester.

\subsection{Application of Polysulfone layer for turbidity removal}

In light of the continuous increase in prices of SW30HR-380 membrane, there was a need to reuse these membranes in other applications. In the current study, we reuse Polysulfone layers of SW30HR-380 Dow Filmtec membrane as a filter for turbidity removal. Polysulfone layer possesses an excellent fabrication with high mechanical, chemical and thermal stability. In addition to a good pore size permitting to its application as a filter for turbidity removal from surface water. The raw water quality and filter clogging conditions were demonstrated.

\subsection{Raw water quality}

The Physico-chemical parameters of the water sample was recorded in Table (1). The level of turbidity and algae count was monitored for the first six months of 2018. The minimum value of water turbidity was observed in February, while it reaches its maximum in April, Figure (7). $\mathrm{pH}$ value ranged from 8 to 8.4 in this period using (WTW, PH 7110, Inolab, Germany) while Total Dissolved Solids (TDS) exceeds 855 ppm after canals purification. Through Polysulfone layer, turbidity value and algae count were 
decreased, while no real change in other parameters was noticed. The factors affecting the filtration process such as a number of layers of the filter, the sample turbidity, total volume of water passed through the filter were studied. Also, the influence of water volume on filter capacity has been studied. The turbidity measurements were done using Turbidimeter (Hanna, Woonsocket, RI, USA). The effect of raw water turbidity is a vital factor to be studied. Raising water turbidity was accompanied with removal increase for turbidity and algae (Fig. 8).

Table (1): Physico-chemical parameters of water sample

\begin{tabular}{|l|c|c|}
\hline Physico-chemical Parameters & Average analysis & $\begin{array}{c}\text { Permissible } \\
\text { limit }\end{array}$ \\
\hline Turbidity $(\mathrm{N} . T . U)$ & 20 & 1 \\
$\mathrm{pH}$ & 8.1 & $6.5-8.5$ \\
Electrical Conductivity $(\mu \mathrm{s} / \mathrm{cm})$ & 643 & 2000 \\
TDS $(\mathrm{mg} / \mathrm{l})$ & 313 & 1000 \\
Total Hardness as $\left(\mathrm{CaCO}_{3}\right)(\mathrm{mg} / \mathrm{l})$ & 158.6 & 500 \\
Total Alkalinity as $\left(\mathrm{CaCO}_{3}\right)(\mathrm{mg} / \mathrm{l})$ & 144 & 250 \\
Chlorides $(\mathrm{mg} / \mathrm{l})$ & 56 & 250 \\
Algae Count $(\mathrm{Unit} / \mathrm{ml})$ & 850 & $\mathrm{Nil}$ \\
\hline
\end{tabular}

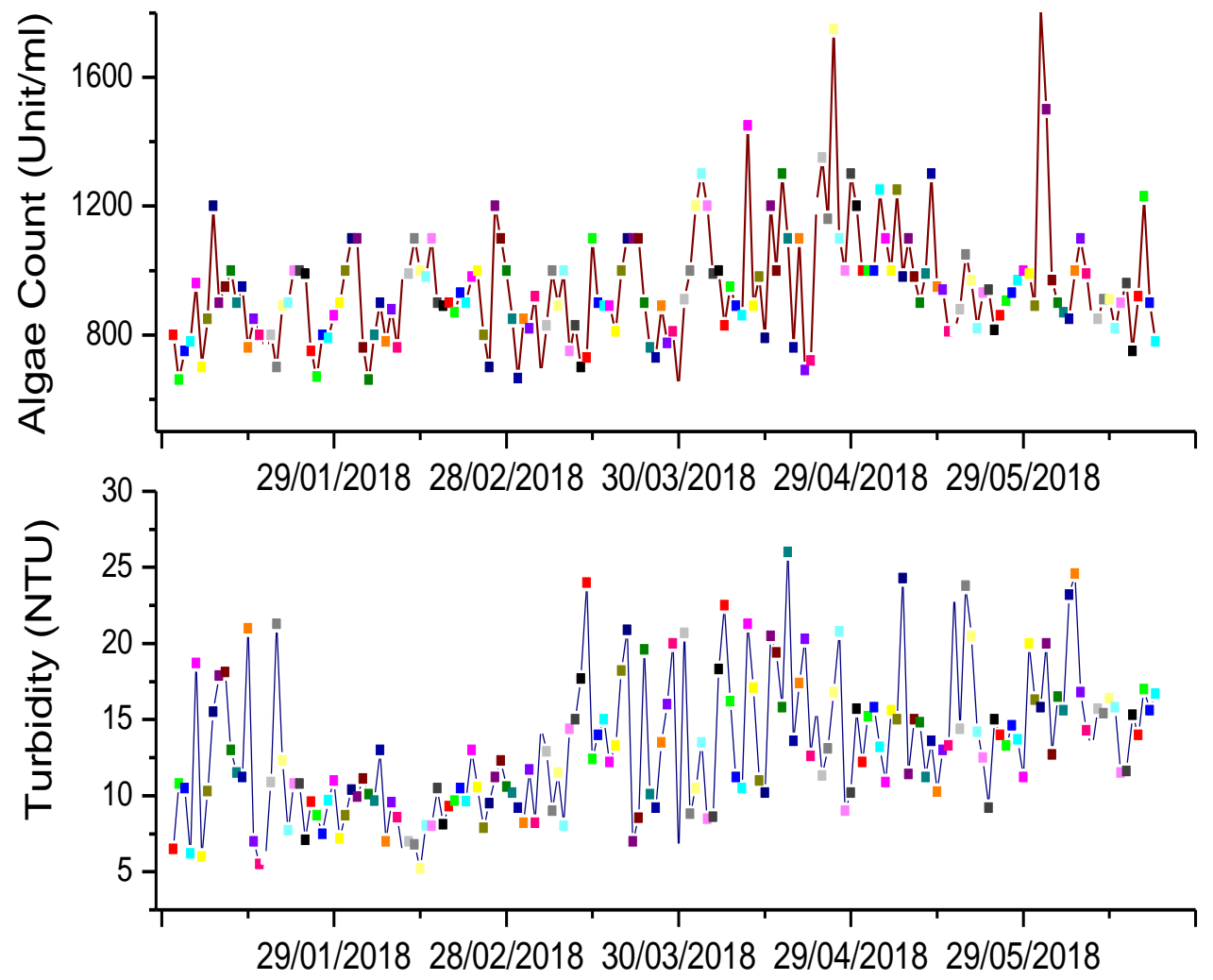

Figure (7): Turbidity and algae count at the area of study (El-Hamam Canal) 


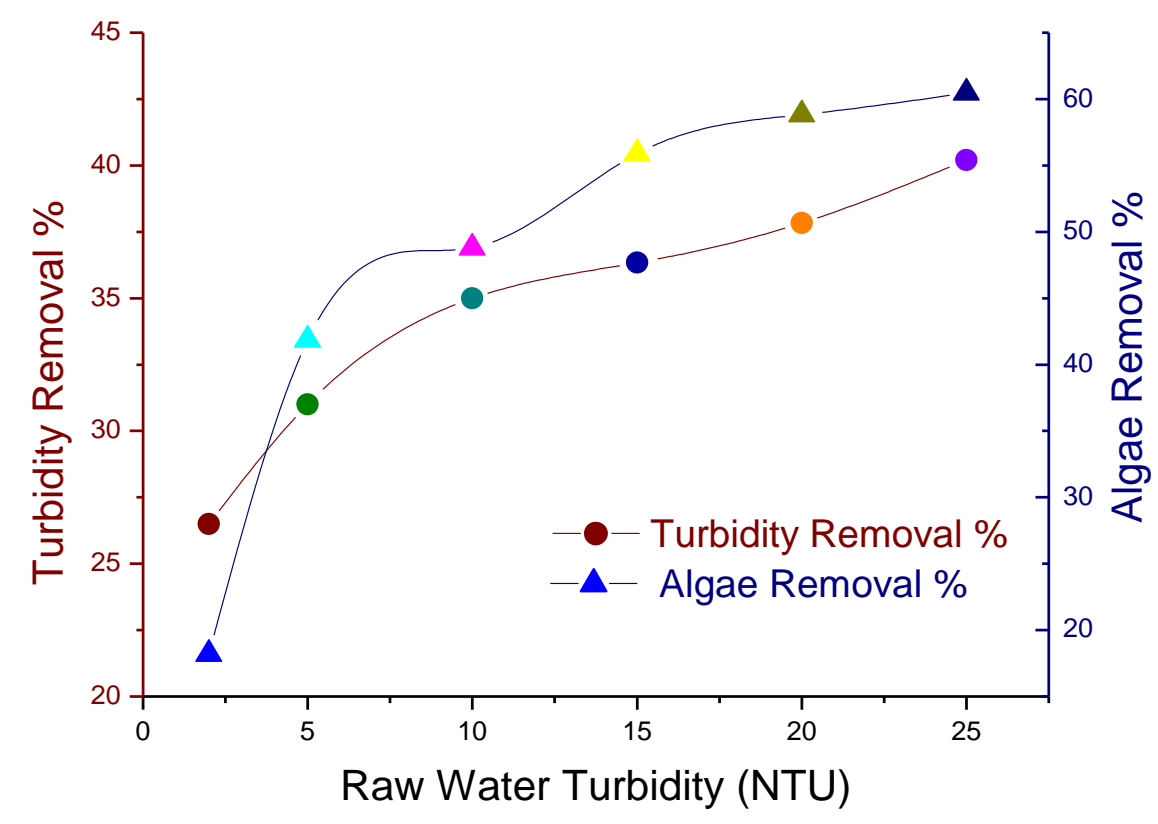

Figure (8): Effect of raw water turbidity on turbidity and algae removal \%, Removal conditions: - [Number of layers $=3$, the total volume of water $=250 \mathrm{ml}$ ]

For water turbidity below 15 NTU, the removal percent was obvious and great which exceeds $35 \%$. For more turbid samples, a slight increase in the removal percent was noticed. So, it is a valid application for surface water filtration since turbidity, in the area of study, the average turbidity recorded 20 NTU. This makes it qualified to be a step of water treatment, even in the pretreatment process. (Abo-El-Enein, et al., 2009 Mohamed, 2009; Badiaa et al.,2010; Farida et al., 2015; Mohamed et al., 2019; Mohamed et al., 2020a; Mohamed et al., 2020b) conducted the removal of algae and turbidity from surface water using conventional methods.

\section{Filter Clogging}

The removal percent increase with water passage through filter layers until the water flow reaches its minimum value after two liters, Figure (9). This behavior refers to the pore size decrease due to trapping suspended particles reducing the pore size of filter disc, causes an increase in turbidity removal accompanied with a sudden decrease in water flow till the clogging of the first layer. The clogging phenomenon resulted from both of a bridging and attachment mechanism in the filter cake. The time required for complete clogging is related to suspended particles, pore size and filtration rate where it is more rapid at high concentration of suspended particles, high flow rate, and small pore size. This disadvantage can be skipped by the control of filter layers replacement or automatic backwashing to recover operational conditions ( Duran-Ros et al., 2009).The filter layer photographs were attached to the Figure (9) in order to show its state during the experiment. The Figure (9) showed the filter capacity increase with water flow where the turbidity deposition on filter surface increase. From the Figure (9), the maximum capacity of the first layer was estimated to be $0.8 \mathrm{NTU} / \mathrm{cm}^{2}$. The process was found to be surface filtration, not a depth filtration as the suspended materials were collected on a filter surface forming a filter cake which reduced the pores size (El-Aassar et al.,2019). 
Thus, the pressure differential required to maintain water flow increased and the filter plates should be cleaned. Also, Filter clogging was affected by the number of layers where the removal percent for both of turbidity and algae count increase with the increase in number of layers. This was expected for the increase of the filtration area, raw water passed through. The behavior similarity of both turbidity and algae count is expected as algae form a portion of water turbidity. In the current study, the removal percent of six layers isn't far from that of five layers, where five layers were found to be sufficient for the bulk portion removal of water turbidity.

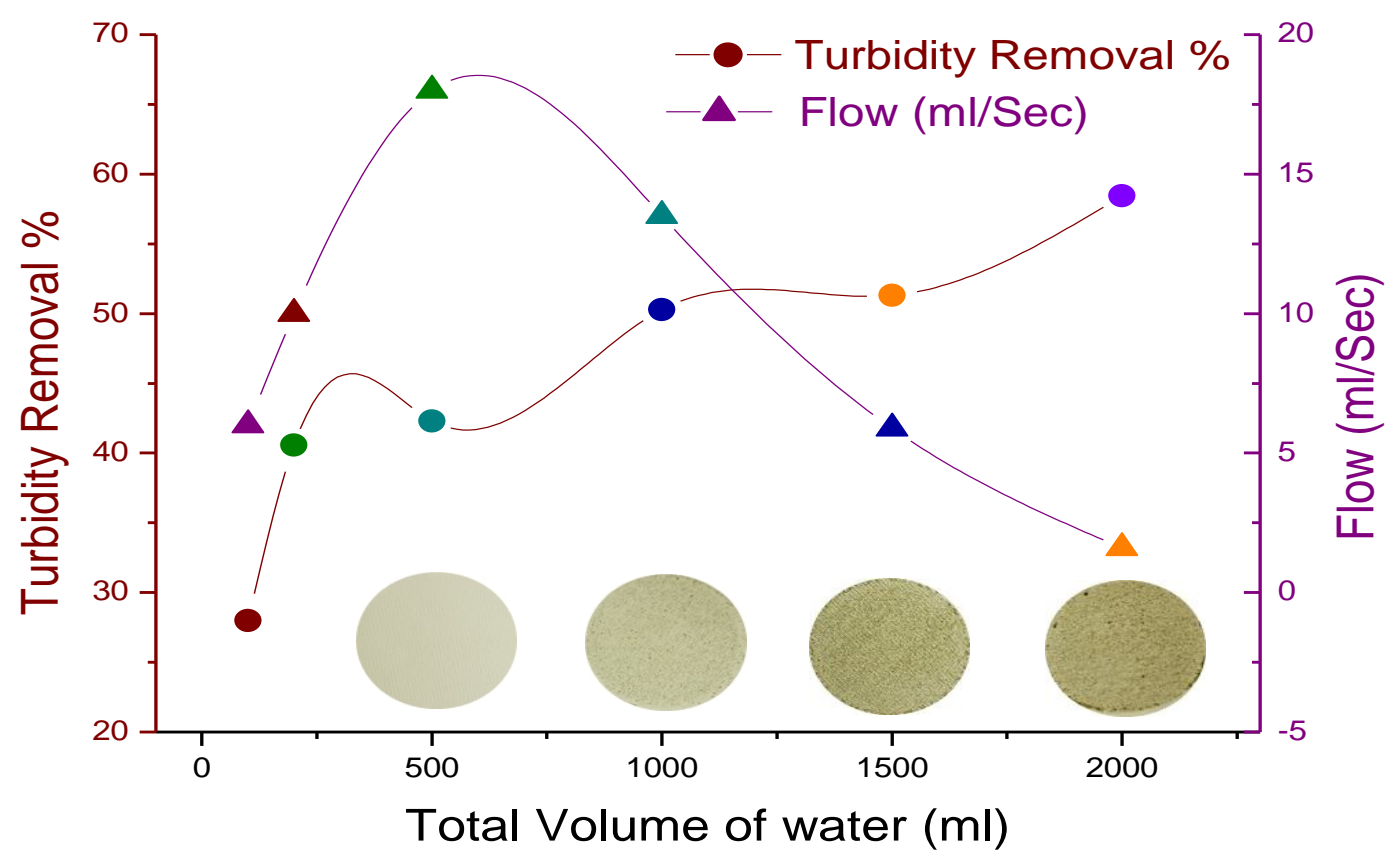

Figure (9): Effect of water volume on turbidity and its influence on flow, Removal conditions: - [Turbidity $=20$ NTU, Algae count $=850$ unit $/ \mathrm{ml}$, Number of layers $=3$ ]

\subsection{The effect of different commercial coagulant dose (mg/l) on the turbidity removal \\ Different commercial coagulants were tested against water turbidity, Figure} (10A). Ferric chloride and Alum have the same directly proportional behavior towards coagulant dose. On the other hand, as shown in Figure (10B), the Hydrex coagulants showed a slight effect on the removal of water turbidity by raising their dose. The Hydrex 67516 showed the highest removal percent while Hydrex 6161 showed unsatisfied performance. Hydrex 6783 showed a negative effect at higher levels of turbidity $(\geq 8$ NTU). Obviously, all tested coagulants achieved higher removal $\%$, at the same turbidity (16 NTU), than that achieved by the used membrane (35\%). But we must take in consideration the availability of the used membrane, the ability of regeneration and the processing time. On contrast, the conventional coagulation process has the advantage of higher flow rate with high volumes of water. 

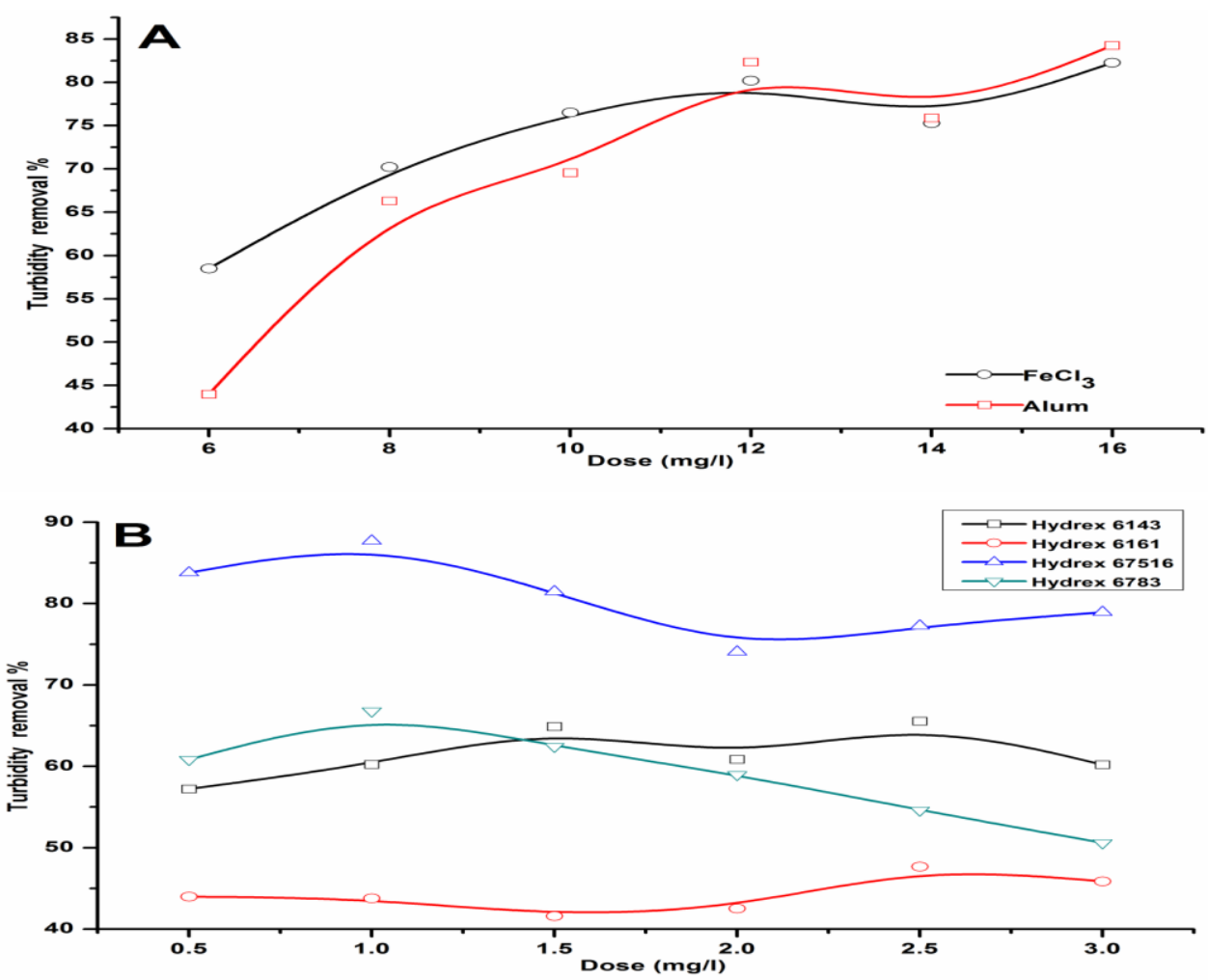

Figure 10: The effect of (A) inorganic and (B) organic coagulants dose (mg/l) on the turbidity removal\%

\section{CONCLUSION}

Water permeated from DOW FILMTEC ${ }^{T M}$ SW30HR-380 membrane meets the standard limits for human health. The membrane showed $99.4 \%$ rejection of chlorides ions of the feed water. Chemical cleaning became not effective, according to permeate data, after a certain period of operation. DOW FILMTECTM SW30HR-380 membrane showed a high chemical stability towards different types of organic solvents, even with heating. SEM photographs were an evidence for the high fabrication of the membrane. The coating layer showed hydrophilic hydroxyl groups appearing in FTIR spectra. Mechanically, the polyamide layer showed the best tensile properties. Application of Polysulfone layer show satisfied results that make it qualified for surface water purification. The removal percentage of turbidity and algae are reached 60 and $80 \%$ respectively. In addition, the blocking of the filter with turbidity accumulation must be taken into consideration and may be cleaned by hypochlorite solution cleaning. Also, the reusing reverse osmosis membrane may be used as an alternative technique for removing turbidity and algae, while on the other hand, it reduces harmful effects and emissions.

\section{ACKNOWLEDGEMENT}

The authors of the current work are sincerely thankful to Faculty of Earth Sciences, Beni-Suef University and College of Science, Jouf University, Sakaka, Saudi Arabia for sharing in this study. The authors thanks also go to the reviewers for their guidance and 
help on this paper. The authors would like to extend their sincere appreciation to the Central laboratory at Jouf University for their support

\section{REFERENCES}

Abo-El-Enein, S.A; Eissa, M.A; Diafullah, H.A.; Rizk, M.R and Mohamed, F. M. (2011). "Utilization of a low cost agro-residue for production of coagulant aids and their applications." Journal of hazardous materials 186(2-3): 1200-1205.

Abo-El-Enein, S.A; Eissa, M.A; Diafullah, H.A.; Rizk, M.R and Mohamed, F. M. (2009). "Removal of some heavy metals ions from wastewater by copolymer of iron and aluminum impregnated with active silica derived from rice husk ash", journal of hazardousmaterials.,172: 574-579

Alsohaimi, I. H.; El-Aassar, M. ; Elzain, A. A.; Alshammari, M. S. and Ali, A. S. (2020). "Development of activated carbon-impregnated alginate* $\beta$ cyclodextrin/gelatin beads for highly performance sorption of 2, 4-dichlorophenol from wastewater." Journal of Materials Research and Technology,

Altaee, A. (2012). "A computational model to estimate the performance of 8 inches RO membranes in pressure vessel." Journal of Membrane and Separation Technology 1(1): 60-71.

Badiaa G.; Djamel G. and Ali S. (2010)"Algae and cyanotoxins removal by coagulation/flocculation: A review", Desal., and Water Treatment, 20: 133-143.

Davenport, D. M.; Ritt, C. L. Verbeke, R.; Dickmann, M. Egger, W.; Vankelecom, I. F. and Elimelech, M. (2020). "Thin film composite membrane compaction in high-pressure reverse osmosis." Journal of Membrane Science: 118268.

Duran-Ros, M.; Puig-Bargués, J.; Arbat, G.; Barragán, J. and de Cartagen, F. R. (2009). "Performance and backwashing efficiency of disc and screen filters in microirrigation systems." Biosystems engineering 103(1): 35-42.

El-Aassar, M.R. and Mohamed, F.M. (2021). "Characterization valorized anthracite and its application in manganese (VII) adsorption from aqueous solution; batch and column studies, Microporous and Mesoporous Materials, 310: (2021) https://doi.org/10.1016/j.micromeso.2020.110641

El-Aassar, M.; Shibraen, M. H.; Abdel-Fattah, Y. R. and Elzain, A. A. (2019). "Functionalization of Electrospun Poly (Acrylonitrile-co-Styrene/Pyrrole) Copolymer Nanofibers for Using as a High-performance Carrier for Laccase Immobilization." Fibers and Polymers 20(11): 2268-2279.

El-Dessouky, H. T. and H. M. Ettouney (2002). Fundamentals of salt water desalination, Elsevier.

El- Aassar, M. R.; Masoud, M. S.; Elkady, M. F. and Elzain, A. A. (2018). "Synthesis, optimization, and characterization of poly (Styrene- co- Acrylonitrile) copolymer prepared via precipitation polymerization." Advances in Polymer Technology 37(6): 2021-2029.

Farida, M.; El-Dars, S. E.; Abdel Rahman,M. A. M. ; Olfat M. A. Salem, El-Sayed A. Abdel-Aal.(2015). "Algal control and enhanced removal in drinking waters in Cairo, Egypt, J Water Health" (2015) 13 (4): 1060-1072.

Gaikwad, V. and G. Munavalli (2019). "Turbidity removal by conventional and ballasted coagulation with natural coagulants." Applied Water Science 9(5): 130. 
Kwak, S. Y.; Jung, Y. S.; Yoon, S. G. and D. W. Ihm (1999). "Details of surface features in aromatic polyamide reverse osmosis membranes characterized by scanning electron and atomic force microscopy." Journal of Polymer Science Part B Polymer Physics 37(13): 1429-1440.

Lee, K. P.; Arnot, T. C. and D. Mattia (2011). "A review of reverse osmosis membrane materials for desalination-development to date and future potential." Journal of Membrane Science 370(1-2): 1-22.

Lomax, I. (2008). "Experiences of Dow in the field of seawater reverse osmosis." Desalination 224(1-3): 111-118.

Mohamed, F.M. (2009). "Treatment of some water pollutants using novel sorbent materials", PhD. Thesis, chemistry Dep. Fac. Of Sci., Ain Shams university.

Mohamed F.M. and Alfalous, K.A. ( 2020). "The effectiveness of activated silica derived from rice husk in coagulation process compared with inorganic coagulants for wastewater treatment". Egyptian Journal of Aquatic Research. https:// doi.org/10.1016/j.ejar.2020.03.004.

Mohamed, F.M.; Nasr El-Deen, F. and Kamal, A. M. (2020A). "The Relationship between Algal Counting and Chemicals Consumption of Conventional Purification Systems at Qena Governorate, Egypt." Egyptian Journal of Aquatic Biology and Fisheries 24(1): 161-172.

Mohamed, F.M.; Kamal, A. M. and Alfalous, K. (2019). "Recycling of Al (III) from Solid Waste as Alum and Alum Derivatives and their Applications in Water and Waste water Treatment." Egyptian Journal of Aquatic Biology and Fisheries 23(5 (Special Issue)): 135-146.

Mohamed, F.M.; Alfalous, and El Gamal, M. (2020b). "Utilization of Poly Inorganic Coagulants Impregnated with Activated Silica Derived from Rice Husk Ash in Treatment of Grey Water", Wat.Ener.Food.Env.J 1,( 2): 1-11 http://dx.doi.org/10.18576/wefej/010101

Mondal, S. and S. R. Wickramasinghe (2008). "Produced water treatment by nanofiltration and reverse osmosis membranes." Journal of Membrane Science 322(1): 162-170.

Nikolay, V. (2013). Desalination Engineering: Planning and Design, McGraw-Hill Professional.

Rice, C. A. and Nuccio, V. (2000). "Water produced with coal-bed methane." US Geological Survey Fact Sheet FS-156-00 2.

Sasikala, S. and Muthuraman, G. (2017). "Turbidity removal from surface water by natural coagulants and its potential application." Iranica Journal of Energy and Environment 8(1): 61-66.

Separations, D. L. (2004). FilmTec ${ }^{\mathrm{TM}}$ Reverse Osmosis Membranes: Technical Manual.

Silverstein, R. M.; Webster, F. X. ; Kiemle, D. J. and Bryce, D. L. (2014). Spectrometric identification of organic compounds, John wiley \& sons.

Starr, J. R.; Stoll, D. C.; Taubenblatt, S. A. and Osborn, D. E. (2019). The politics of scarcity: Water in the Middle East, Routledge.

Yang, Z.; Zhou, Y.; Feng, Z.; Rui,X.; Zhang, T. and Zhang, Z. (2019). "A review on reverse osmosis and nanofiltration membranes for water purification." Polymers 11(8): 1252. 